\title{
The serum insulin and plasma glucose responses to milk and fruit products in Type 2 (non-insulin-dependent) diabetic patients
}

\author{
M.C. Gannon, F.Q. Nuttall, P. A. Krezowski, C.J. Billington and S. Parker \\ Metabolic-Endocrine Section, Minneapolis Veterans Administration Medical Center, Minneapolis, Minnesota, USA
}

Summary. The plasma glucose and serum insulin responses were determined in untreated Type 2 (non-insulin-dependent) diabetic patients following the ingestion of foods containing sucrose, glucose, fructose or lactose in portions that contained $50 \mathrm{~g}$ of carbohydrate. The results were compared to those obtained following the ingestion of pure fructose, sucrose, glucose + fructose and lactose. The objectives were to determine 1) if the glucose response to naturally occurring foods could be explained by the known carbohydrate content, and 2) whether the insulin response could be explained by the glucose response. The glucose response was essentially the same whether the carbohydrate was given as a pure substance, or in the form of a naturally occurring food. The glucose response to each type of carbohydrate was that expected from the known metabolism of the constituent monosaccharides. The glucose areas following the ingestion of the foods were:
Study 1: glucose 11.7 , orange juice 7.3 , sucrose 5.2 , glucose + fructose 6.3 , and fructose $0.7 \mathrm{mmol} \cdot \mathrm{h} / 1$; Study 2 : glucose 14.6, orange juice 7.3, apples 5.5, and apple juice $4.7 \mathrm{mmol} \cdot \mathrm{h} / \mathrm{l}$; Study 3: glucose 12.6, ice cream 8.1, milk 3.7, and lactose $4.1 \mathrm{mmol} \cdot \mathrm{h} / \mathrm{l}$. The insulin response was greater than could be explained by the glucose response for all meals except apples. Milk was a particularly potent insulin secretagogue; the observed insulin response was approximately 5 -fold greater than would be anticipated from the glucose response. In summary, the plasma glucose response to ingestion of fruits and milk products can be predicted from the constituent carbohydrate present. The serum insulin response cannot.

Key words: glycaemic index, diabetes, meals, diets, sucrose, fructose, milk, lactose, glucose.
There is considerable interest in the plasma glucose response to carbohydrate containing foods as a basis for dietary recommendations for diabetic patients. This has been stimulated by the studies of Otto et al. [1] and Jenkins et al. [2]. They have determined the plasma glucose response to a standardized amount of carbohydrate present in a variety of different foods. Considerable differences in the response have been noted. We have been interested in rationalizing the plasma glucose response to different carbohydrate containing foods based upon the chemical composition, physical state, and the known digestibility of the major carbohydrate present in a food, as well as the metabolic response to the ingested carbohydrate. Principles derived from such studies should obviate the need to test the plasma glucose response to a large number of different carbohydrate containing foods and allow simplification of dietary recommendations for persons with diabetes. In addition, we have had a keen interest in the serum insulin response to different types of foods, since this information also could be useful in the design of a dietary regimen for Type 2 diabetic patients $[3,4]$.
In this communication we present plasma glucose and serum insulin data obtained following single meal ingestion of $50 \mathrm{~g}$ of either fructose, sucrose, a mixture of fructose + glucose or lactose. The results are compared with those obtained following the ingestion of foods in which these mono- and disaccharides represent the major carbohydrate present. Data were obtained for $5 \mathrm{~h}$ after ingestion of the meal, since we previously had shown that this is the time required for the plasma glucose concentration to return to a fasting value after ingestion of $50 \mathrm{~g}$ glucose in such patients. An additional reason for studying patients for $5 \mathrm{~h}$ is that the serum insulin concentration frequently is still modestly elevated at that time, so a more accurate assessment of the overall insulin response is obtained.

\section{Subjects and methods}

Thirteen untreated diabetic subjects were studied in a metabolic unit. All the subjects met the National Diabetes Data Group criteria [5] for the diagnosis of Type 2 diabetes mellitus. The mean age was $61 \pm 3$ years with a range of 37 to 73 years. The mean body mass index was 
Table 1. Clinical characteristics

\begin{tabular}{|c|c|c|c|c|c|c|c|}
\hline Patients & Study 1 & Study 2 & Study 3 & $\mathrm{HbA}_{1 \mathrm{c}}(\%)^{\mathrm{a}}$ & $\mathrm{BMI}\left(\mathrm{kg} / \mathrm{m}^{2}\right)$ & Duration & Concommitant diseases \\
\hline 1. B.L. & & $\mathrm{X}$ & & 8.2 & 31.9 & New onset & $\begin{array}{l}\text { Hypertension, gout peptic ulcer } \\
\text { disease }\end{array}$ \\
\hline 2. G.B. & & $\mathrm{X}$ & $\mathrm{X}$ & 8.4 & 38.3 & 8 years & Hypertension, CHD \\
\hline 3. R.W. & & $\mathrm{X}$ & & 9.2 & 31.1 & New onset & Hypertension \\
\hline 4. M.C. & & $\mathrm{X}$ & & 10.5 & 25.5 & 6 years & $\begin{array}{l}\text { Peripheral neuropathy, retinopa- } \\
\text { thy, } \\
\text { Hypertension }\end{array}$ \\
\hline 5. T.A. & & & $\mathrm{X}$ & 8.2 & 31.1 & 1 year & None \\
\hline 6. F.S. & $X$ & $\mathrm{X}$ & $\mathrm{X}$ & 7.7 & 32.4 & 1 year & None \\
\hline 7. W.M. & & $\mathrm{X}$ & & 7.7 & 36.0 & 2 months & None \\
\hline 8. K.S. & $\mathrm{X}$ & $\mathrm{X}$ & $\mathrm{X}$ & 6.6 & 28.4 & 2.5 years & Hypertension, $\mathrm{CHD}$ \\
\hline 9. J.H. & $\mathrm{X}$ & & $\mathrm{X}$ & 8.9 & 38.0 & 3 years & None \\
\hline 10. H.B. & $\mathrm{X}$ & & $\mathrm{X}$ & 10.5 & 31.1 & 10 years & Mild peripheral neuropathy \\
\hline 11. C.S. & $\mathrm{X}$ & & & 7.9 & 26.8 & 2 years & Hypertension, gout \\
\hline 12. J.J. & $\mathrm{X}$ & & & 6.9 & 41.3 & 4 month & $\begin{array}{l}\text { CHD, gout } \\
\text { hypertension }\end{array}$ \\
\hline 13. L.G. & $\mathrm{X}$ & & $\mathrm{X}$ & 7.2 & 26.8 & 3 years & $\begin{array}{l}\text { CVA-remote, COPD } \\
\text { hypertension }\end{array}$ \\
\hline
\end{tabular}

${ }^{\text {a }}$ Normal $=4.2-6.2 \%$

$32.2 \pm 1.4 \mathrm{~kg} / \mathrm{m}^{2}$. All the subjects signed an informed consent form, and the study was approved by the Medical Center Committee on Human Subjects. All the participants had ingested a diet containing at least $200 \mathrm{~g}$ carbohydrate per day with adequate food energy for three days prior to testing. None of the subjects were on treatment with either oral hypoglycaemic agents or insulin prior to study. In general, these individuals were sedentary. Some of the pertinent clinical characteristics of these patients are listed in Table 1.

After an overnight fast of $8-10 \mathrm{~h}$, an indwelling catheter was inserted into an antecubital vein and kept patent with $100 \mathrm{U}$ heparin flushed into the catheter after each sample was obtained. Test meals were given at 08.00 hours.

Three studies were done:

Study 1 (Sucrose Foods). Seven Type 2 diabetic subjects, mean age $61 \pm 3$ years (range 53-72) with a mean body mass index of $32.1 \pm 2.1 \mathrm{~kg} / \mathrm{m}^{2}$, were given a meal containing $50 \mathrm{~g}$ carbohydrate as glucose, fructose, orange juice, or $25 \mathrm{~g}$ glucose $+25 \mathrm{~g}$ fructose, or $47.5 \mathrm{~g}$ sucrose in random order. The glucose was given as a standard glucose solution. The sucrose and fructose (purchased from Sigma Chemical Company, St. Louis, Mo, USA) were dissolved in approximately 0.241 of water. The orange juice was a frozen concentrate reconstituted to 0.501 . The glucose, fructose and sucrose were supplemented with 0.241 of water to equalize the volume. The orange juice contained $3 \mathrm{~g}$ protein and only a trace of fat per $50 \mathrm{~g}$ carbohydrate as calculated from food tables $[6,7]$. The carbohydrate in orange juice is approximately half glucose and half fructose, either free or as the dissacharide sucrose [8].

Study 2 (Sucrose Foods). Seven Type 2 diabetic subjects, mean age $60 \pm 4$ years (range 37-69) with a mean body mass index of $31.9 \pm 1.6 \mathrm{~kg} / \mathrm{m}^{2}$, were given in random order a meal containing $50 \mathrm{~g}$ carbohydrate as glucose, brange juice, apple juice or raw apples, as calculated from food tables $[6,7]$. The glucose was given as a standard solution. The orange juice was given as indicated for Study I. The volume of apple juice ingested was 0.421 . Raw ripe apples were sliced and eaten with the skin still intact. The apple juice contained a trace protein and $0.4 \mathrm{~g}$ fat. The raw apples contained $1.3 \mathrm{~g}$ protein and a trace fat.

Two of the subjects in Study 1 were tested with apples and apple juice and are included as subjects in Study 2 .

Study 3 (Lactose Foods). Seven Type 2 diabetic subjects, mean age $64 \pm 3$ years (range 53-73) with a mean body mass index of
$32.2 \pm 1.7 \mathrm{~kg} / \mathrm{m}^{2}$, were given in random order a meal consisting of $50 \mathrm{~g}$ carbohydrate as glucose, skim milk, lactose or ice cream as calculated from food tables $[6,7]$. The glucose was given as a standard glucose solution. The lactose was a powder dissolved in $0.95 \mathrm{l}$ of water ( $a$-lactose purchased from Sigma Chemical Co., St. Louis, Mo, USA). The volume of skim milk given also was 0.951 . The ice cream was served frozen with up to 0.471 of water or decaffeinated coffee. The skim milk contained $34 \mathrm{~g}$ protein and $1 \mathrm{~g}$ fat per $50 \mathrm{~g}$ carbohydrate serving. The ice cream carbohydrate was $67 \%$ sucrose and $33 \%$ lactose. It also contained $7.4 \mathrm{~g}$ protein and $13.2 \mathrm{~g}$ fat (milk and butter fats) per $50 \mathrm{~g}$ carbohydrate.

For all studies, blood for glucose and insulin was drawn at 0,30 $60,120,180,240$ and $300 \mathrm{~min}$ after the ingestion of the test meal. Plasma glucose was determined by a glucose oxidase method using a Beckman glucose analyzer (Beckman Instruments, Inc., Fullerton, Calif, USA). Serum immunoreactive insulin was measured by a standard double antibody radioimmunoassay (RIA) method using kits produced by Endotech, Inc., Louisville, Ky, USA.

The test meal was given for breakfast. The remainder of the day the patient consumed a regular hospital diet ad libitum. This diet provides $2600 \mathrm{KCal}$, with approximately $280 \mathrm{~g}$ carbohydrate, $105 \mathrm{~g}$ protein, $115 \mathrm{~g}$ fat and $15-20 \mathrm{~g}$ fibre. The patients selected the amount of food they wished to eat each day from this diet. The time between the test meals was variable, but generally the breakfasts were consumed on sequential days for up to 5 days. After 2-3 days of regular hospital meals, the patients participating in more than one study were tested again.

The glucose and insulin areas above the fasting baseline were determined by planimetry. Areas below the baseline were subtracted from areas above the fasting baseline to give a net area.

The relationship between the glucose response to a test meal and the glucose and insulin response to $50 \mathrm{~g}$ glucose was used to predict the insulin response to a test meal. The following formula was used:

\section{Glucose Area for Glucose $=$ Glucose Area for Test}

Insulin Area for Glucose $=\frac{\text { Insulin Area for Test }}{\text { Int }}$

Where: Glucose Area for Glucose = the measured area under the glucose curve following the ingestion of $50 \mathrm{~g}$ glucose

Insulin Area for Glucose = the measured area under the insulin curve following the ingestion of $50 \mathrm{~g}$ glucose 
Glucose Area for Test=the measured area under the glucose curve following the ingestion of the test meal

Insulin Area for Test is calculated based on the 3 values listed above.

The predicted insulin value using the above formula was compared to the observed insulin area for each meal.

\section{Statistical analysis}

Student's two-tailed $t$-test for paired variates was used for analysis of statistical significance. Significance was established at $p<0.05$. Data are presented as the mean \pm standard error the mean (SEM).

\section{Results}

\section{Sucrose foods (Study I)}

Plasma glucose. After the ingestion of $50 \mathrm{~g}$ glucose (Fig.1), mean plasma glucose increased from a basal level of $8.7 \pm 0.7 \mathrm{mmol} / 1$ to a peak value of $5.0 \pm$ $0.9 \mathrm{mmol} / 1$ above the basal level at $1 \mathrm{~h}$. It then returned to near basal levels at $4 \mathrm{~h}$. Following the ingestion of sucrose, plasma glucose increased by $4.4 \pm 0.6 \mathrm{mmol} / 1$ at $1 \mathrm{~h}$. It then decreased below baseline by $3 \mathrm{~h}$ and was $1.2 \pm 0.5 \mathrm{mmol} / \mathrm{l}$ below baseline at $5 \mathrm{~h}$. After the ingestion of the glucose + fructose meal or orange juice, the results were similar. After the ingestion of $50 \mathrm{~g}$ fructose, the mean plasma glucose increased by $1.9 \pm 0.2 \mathrm{mmol} / 1$ at $1 \mathrm{~h}$. It then decreased to basal levels at $3 \mathrm{~h}$ and decreased to $1.3 \pm 0.5 \mathrm{mmol} / 1$ below baseline at $5 \mathrm{~h}$. The maximal increase in glucose concentration after fructose was significantly less than the peak values for all of the other meals $(p<0.01)$.

Serum insulin. Following the ingestion of glucose (Fig.2), the mean serum insulin increase was $37 \pm$ $11 \mu \mathrm{U} / \mathrm{ml}$ at $1 \mathrm{~h}$ from a basal value of $19 \pm 1 \mu \mathrm{U} / \mathrm{ml}$. It then decreased slowly to near a basal level by $5 \mathrm{~h}$. After the ingestion of sucrose, the serum insulin peak was similar, but occurred at $30 \mathrm{~min}$. Following the ingestion of glucose +fructose, the peak was somewhat less than after glucose; after the ingestion of orange juice, it was the greatest observed with these meals $(44 \pm 11 \mu \mathrm{U} / \mathrm{ml}$ above baseline). The increase after orange juice was significantly greater than after glucose plus fructose ingestion $(p<0.05)$, but it was not significantly greater than for sucrose or glucose. Following the ingestion of fructose, the maximal serum insulin was significantly lower than the peak values for any of the other meals $(p<$ $0.05)$.

Glucose and insulin areas. The mean glucose area integrated over the $5 \mathrm{~h}$ of study following the glucose meal was significantly greater $(p<0.01)$, and the area for the fructose meal was significantly smaller $(p<0.01)$, than the other meals (Fig. 3).

The mean insulin area integrated over the $5 \mathrm{~h}$ of study following the glucose meal was significantly greater than the mean areas for the other 4 meals $(p<$

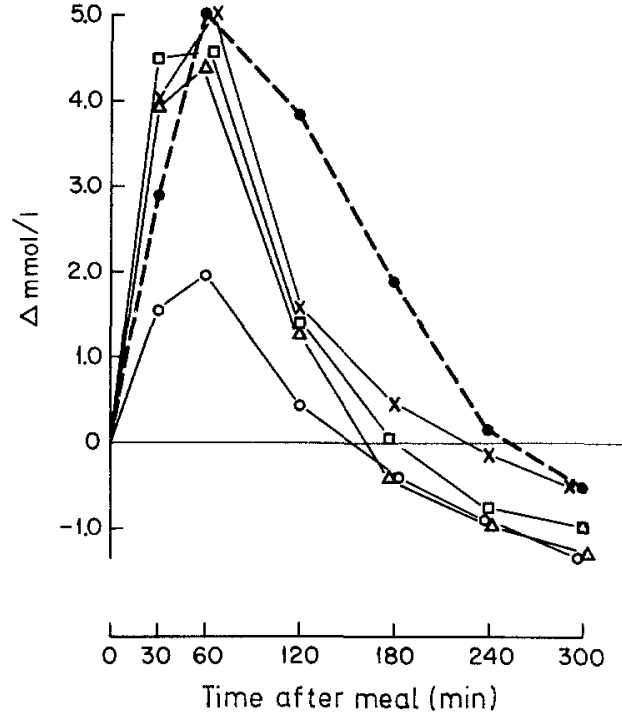

Fig. 1. Plasma glucose response in 7 Type 2 diabetic patients to $50 \mathrm{~g}$ carbohydrate in the form of glucose, fructose, glucose + fructose, sucrose and orange juice, measured as change from basal values. The mean fasting glucose concentration was $8.7 \pm 0.7 \mathrm{mmol} / \mathrm{l}$. cose, $x=$ orange juice, $\Delta=$ sucrose,$\quad \square=$ glucose + fructose, $\mathrm{O}=$ fructose

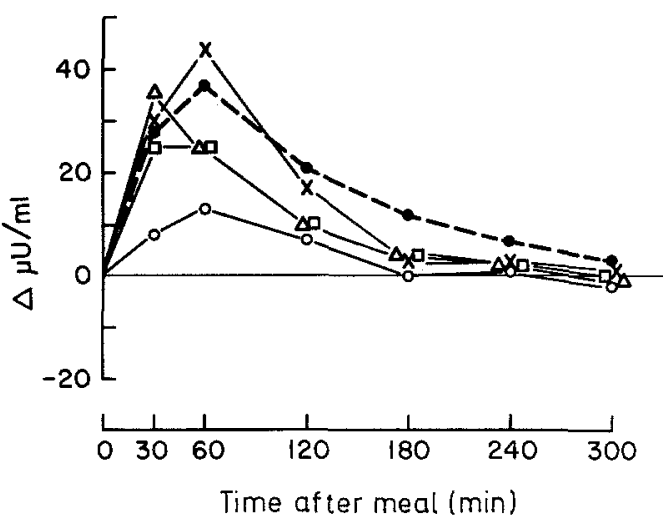

Fig. 2. Serum insulin responses to the ingestion of $50 \mathrm{~g}$ carbohydrate in the form of glucose, fructose, glucose + fructose, sucrose and orange juice measured as the change from basal values in 7 Type 2 diabetic patients. The mean fasting insulin concentration was $19 \pm$ $1 \mu \mathrm{U} / \mathrm{ml}$. - glucose, $x=$ orange juice, $\Delta=$ sucrose, $\square=$ glucose + fructose, $\mathrm{O}=$ fructose

0.01 for all except glucose + fructose, where $p<0.02$ ). The mean insulin area for the fructose meal was significantly smaller than the mean areas for the other 4 meals $(p<0.01$ for all except glucose + fructose) where $p<$ $0.05)$.

Predicted vs observed insulin area. The difference between the predicted and observed insulin area was significantly different for sucrose $(p<0.05)$ and fructose $(p<0.05)$ compared to glucose (Fig. 4).

\section{Sucrose foods (Study 2)}

Plasma glucose. Following the ingestion of $50 \mathrm{~g}$ glucose (Fig.5) the mean plasma glucose increased by $6.2 \pm$ 
$0.7 \mathrm{mmol} / 1$ at $1 \mathrm{~h}$ from a mean basal level of $8.6 \pm$ $0.6 \mathrm{mmol} / 1$ in this group of subjects. It then returned to the fasting level at $5 \mathrm{~h}$. Following the ingestion of raw apples, apple juice and orange juice, the increase was less; the glucose concentration returned to, or below, the baseline by $4 \mathrm{~h}$. The peak value for the apples and apple juice were significantly less than for the glucose meal $(p<0.01)$.

Serum insulin. Following the ingestion of glucose, the serum insulin increased by $55 \pm 17 \mu \mathrm{U} / \mathrm{ml}$ at $1 \mathrm{~h}$ from a mean initial concentration of $19 \pm 1 \mu \mathrm{U} / \mathrm{ml}$ (Fig. 6). It then decreased, but remained above the fasting level at $5 \mathrm{~h}$. After the ingestion of orange juice, the rise was modestly greater and the decrease was more rapid. Following the ingestion of the raw apples and apple juice, the insulin rise was much less than following glucose or

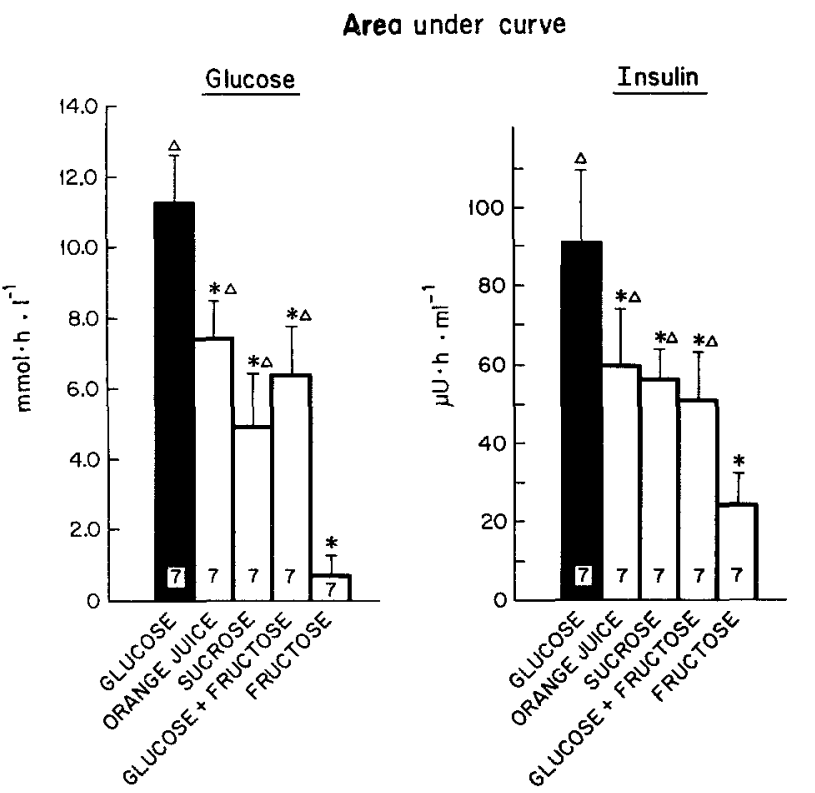

Fig.3. Net mean areas for plasma glucose and insulin determined over $5 \mathrm{~h}$ after the ingestion of $50 \mathrm{~g}$ carbohydrate in the form of glucose, fructose, glucose + fructose, sucrose and orange juice. *Statistically different from glucose $(p<0.01), \Delta$ statistically different from fructose $(p<0.01)$ orange juice, and returned to baseline by $5 \mathrm{~h}$. The peak values for apple and apple juice were significantly less than for the glucose meal $(p<0.05)$.

Glucose and insulin areas. The mean glucose concentration integrated over the $5 \mathrm{~h}$ of study for the $50 \mathrm{~g}$ glucose meal was significantly greater than the mean area for orange juice, apples and apple juice $(p<0.01)$ (Fig. 7). The mean glucose area following ingestion of orange juice was significantly less than the mean area for glucose $(p<0.01)$, and significantly greater than the mean area for apples and apple juice $(p<0.01)$. The areas under the insulin curves were similar for glucose and orange juice, but significantly less for apples and apple juice $(p<0.01)$.

Predicted vs observed insulin area. The difference between the predicted and observed insulin area was different for orange juice $(p<0.02)$ and apple juice $(p<$ 0.01) (Fig.4).

\section{Lactose foods (Study 3)}

Plasma glucose. The mean fasting plasma glucose was $8.9 \pm 0.7 \mathrm{mmol} / 1$ for the $50 \mathrm{~g}$ glucose meal. Following the ingestion of $50 \mathrm{~g}$ glucose, the plasma glucose increased by $5.5 \pm 1.1 \mathrm{mmol} / 1$ at $1 \mathrm{~h}$ (Fig. 8). It then returned to the basal level after $4 \mathrm{~h}$. Following the ingestion of $50 \mathrm{~g}$ carbohydrate as milk, or $50 \mathrm{~g}$ lactose, the increase in plasma glucose was less than for glucose ingestion alone; it decreased to basal levels by $3 \mathrm{~h}$, and then continued to decrease to a level $1.2 \pm 0.2 \mathrm{mmol} / 1$ below basal levels at the end of $5 \mathrm{~h}$. Following the ingestion of $50 \mathrm{~g}$ carbohydrate as ice cream, the plasma glucose response was intermediate between glucose alone and lactose or ice cream, returning to baseline at $4 \mathrm{~h}$.

Serum insulin. Serum insulin responses to glucose and ice cream were similar. There was an increase of $36 \pm$ $10 \mu \mathrm{U} / \mathrm{ml}$ at $1 \mathrm{~h}$ after the ingestion of glucose from a basal level of $19 \pm 1 \mu \mathrm{U} / \mathrm{ml}$ (Fig. 9), followed by a slow decrease toward basal levels. After the ingestion of

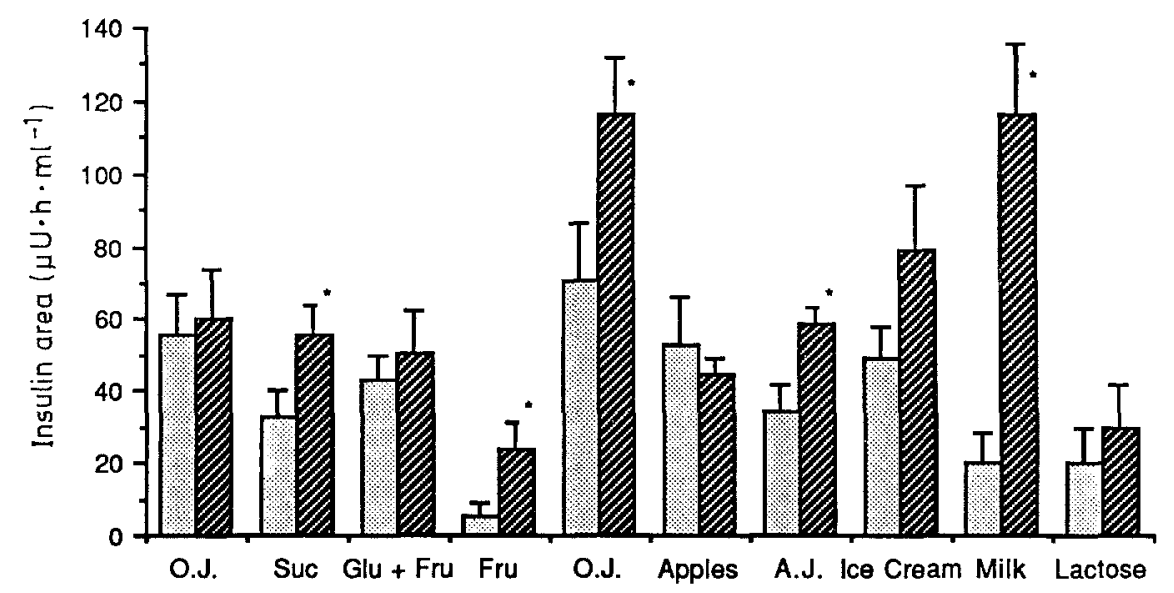

Fig.4. Predicted vs observed insulin areas. predicted response, $\mathbb{Z}$ observed response. The predicted value was calculated as described in the Methods Section. *Statistical difference between the predicted and observed value. $p<$ 0.05 for sucrose and fructose, $p<0.02$ for orange juice, $p<0.01$ for apple juice and milk. $n=7$ for all meals. The first 4 sets of bars are data from Study 1: (O.J.= orange juice, suc $=$ sucrose, glu + fru $=$ glucose + fructose, fru $=$ fructose). The next 3 sets of bars are data from Study 2: (O.J. = orange juice, A.J. = apple juice). The last 3 sets of bars are data from Study 3 


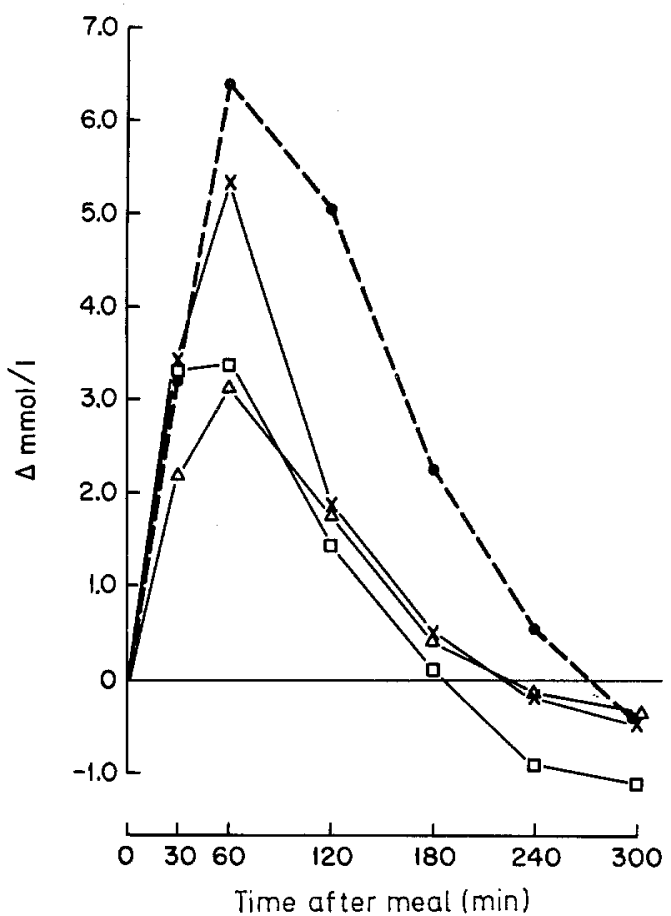

Fig.5. Plasma glucose responses in 7 Type 2 diabetic patients to $50 \mathrm{~g}$ carbohydrate in the form of glucose, raw apples, apple juice and orange juice, measured as change from basal values. The mean fasting glucose concentration was $8.6 \pm 0.6 \mathrm{mmol} / \mathrm{l} . \quad=$ glucose, $x=$ orange juice, $\Delta=$ apples, $\square=$ apple juice

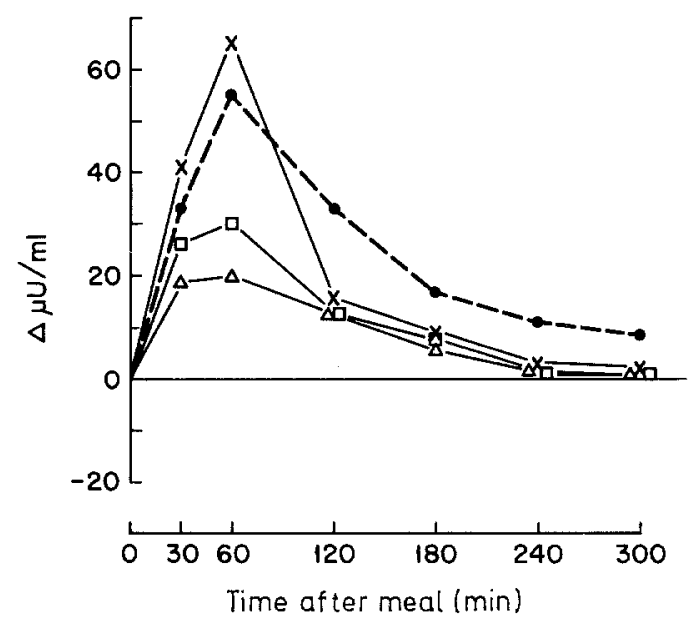

Fig. 6. Serum insulin responses to the ingestion of $50 \mathrm{~g}$ carbohydrate in the form of glucose, raw apples, apple juice and orange juice, measured as the change from basal values in 7 Type 2 diabetic patients. The mean fasting insulin concentration was $19 \pm 1 \mu \mathrm{U} / \mathrm{ml} .0$ glucose, $x=$ orange juice, $\Delta=$ apples, $\square=$ apple juice

milk, the serum insulin increased by $54 \pm 12 \mu \mathrm{U} / \mathrm{ml}$ at $1 \mathrm{~h}$. It then returned to near basal levels by $5 \mathrm{~h}$. Following the ingestion of lactose, the serum insulin response was much less than with the other 3 meals and returned to baseline by $3 \mathrm{~h}$.

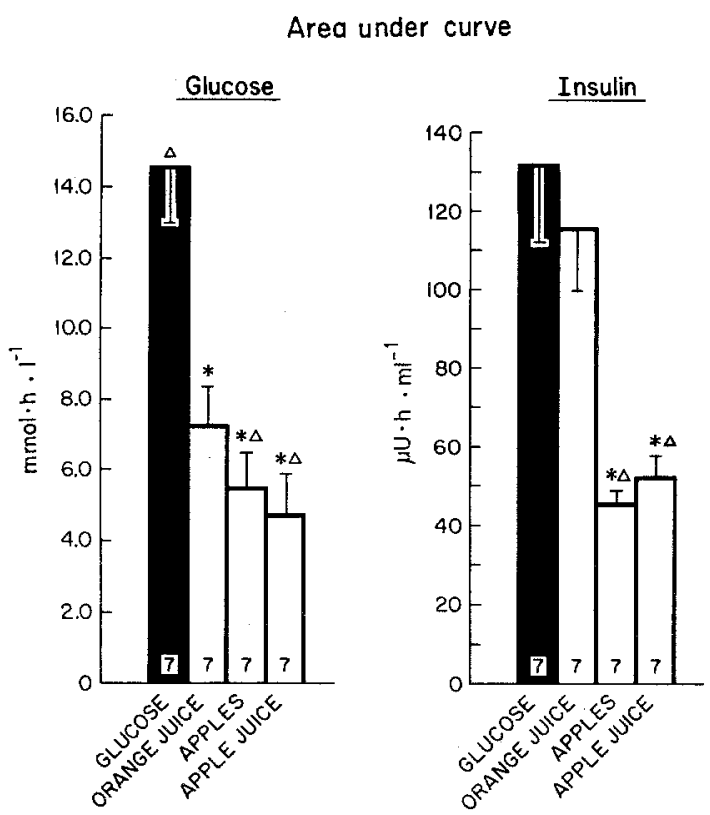

Fig.7. Net mean areas for plasma glucose and insulin determined over $5 \mathrm{~h}$ after the ingestion of $50 \mathrm{~g}$ carbohydrate in the form of glucose, raw apples and apple juice. *Statistically different from glucose $(p<0.01), \Delta$ statistically different from orange juice $(p<0.01)$

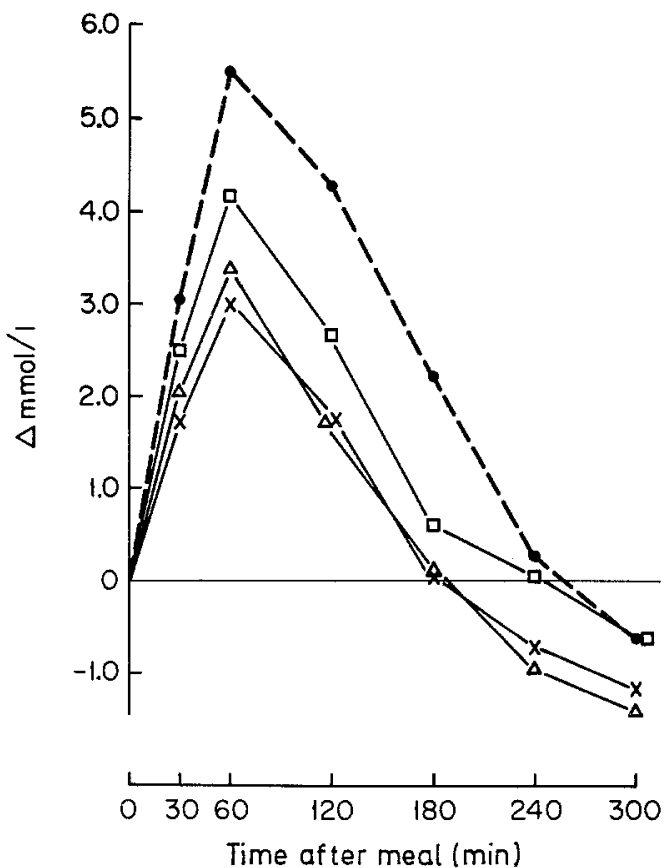

Fig.8. Plasma glucose responses in 7 Type 2 diabetic patients to $50 \mathrm{~g}$ carbohydrate in the form of glucose, skim milk, lactose or ice cream, measured as change from basal values. The mean fasting glucose concentration was $8.9 \pm 0.7 \mathrm{mmol} / \mathrm{l} . \quad=$ glucose,$x=$ milk, $\Delta=$ lactose, $\square=$ ice cream

Glucose and insulin areas. The mean glucose concentration integrated over the $5 \mathrm{~h}$ of study for the $50 \mathrm{~g}$ glucose meal was $12.6 \pm 1.6 \mathrm{mmol} \cdot \mathrm{h} \cdot 1^{-1}$ (Fig. 10). The plasma glucose area for glucose was significantly greater than for the other 3 meals $(p<0.05$ for ice cream, $p<0.01$ for 


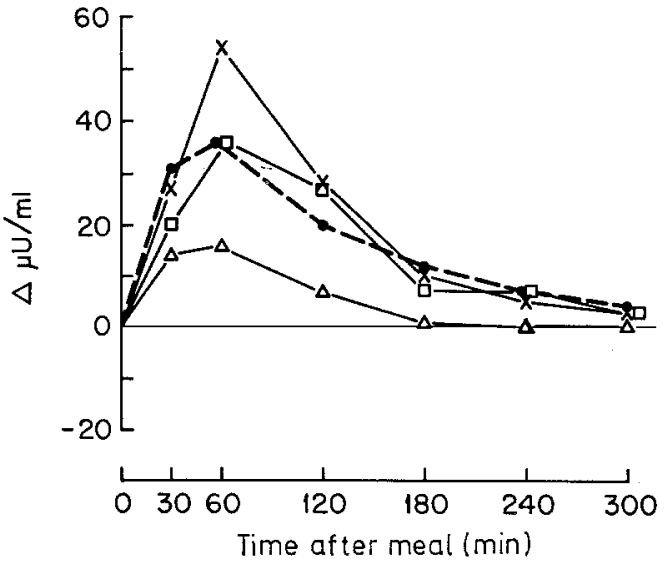

Fig.9. Serum insulin responses to the ingestion of $50 \mathrm{~g}$ carbohydrate in the form of glucose, skim milk, lactose and ice cream measured as the change from basal values in 7 Type 2 diabetic patients. The mean fasting insulin concentration was $19 \pm 1 \mu \mathrm{U} / \mathrm{ml}$. $\bullet=$ glucose, $x=$ milk, $\Delta=$ lactose,$\square=$ ice cream

\section{Area under curve}
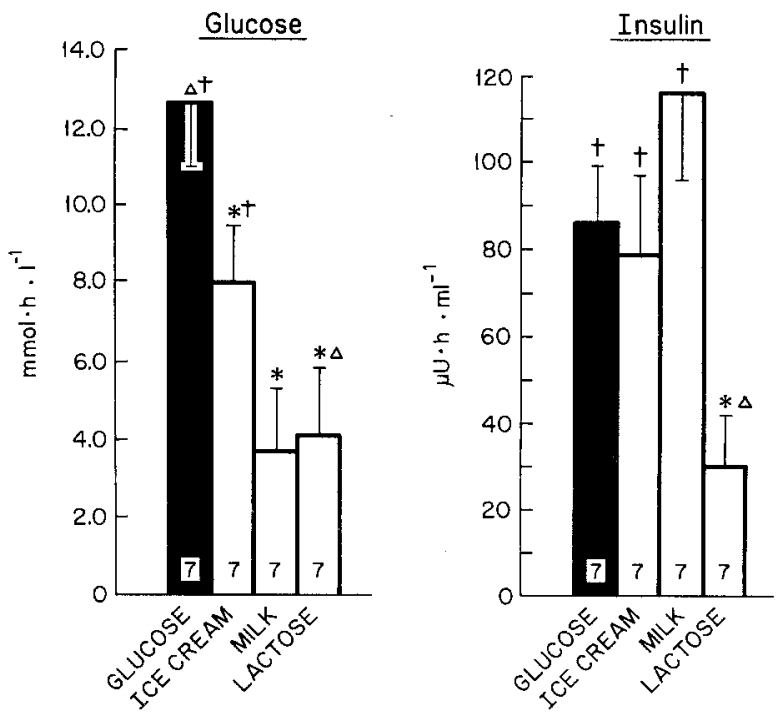

Fig. 10. Net mean areas for plasma glucose and insulin determined over $5 \mathrm{~h}$ after the ingestion of $50 \mathrm{~g}$ carbohydrate in the form of glucose, skim milk, lactose and ice cream. *Statistically different from glucose, ( $p<0.05$ for ice cream, $p<0.01$ for milk and lactose), $\Delta$ statistically different from ice cream $(p<0.05$ for lactose $)+$ significantly different from lactose $(p<0.05$ for ice cream, $p<0.01$ for milk and glucose)

milk and lactose). The mean plasma glucose area for the ice cream was significantly greater than that for the lactose meal $(p<0.05)$.

The mean serum insulin area integrated over the $5 \mathrm{~h}$ of study for the $50 \mathrm{~g}$ glucose meal was $86 \pm 13 \mu \mathrm{U} \cdot \mathrm{h}$. $\mathrm{ml}^{-1}$. The mean insulin areas for glucose, milk and ice cream were not significantly different from each other. The mean insulin area for the lactose was significantly smaller than for the other 3 meals $(p<0.05$ for ice cream, $p<0.01$ for milk and glucose).

Predicted vs observed insulin area. The difference between the predicted and observed insulin area was sig- nificantly different for milk $(p<0.05)$ (Fig. 4). The observed value for skim milk was approximately five-fold greater than the predicted.

\section{Discussion}

Several investigators have reported that fructose ingestion results in a plasma glucose rise which is considerably less than that following the ingestion of a comparable amount of glucose by normal [9-11], glucose intolerant, or non-insulin-requiring mildly diabetic persons [11]. However, the difference in glucose areas was not quantitated. In the present study, the plasma glucose area above the fasting baseline after fructose ingestion, integrated over $5 \mathrm{~h}$, was only $6 \%$ of that determined after glucose ingestion. These results are as might be expected if the metabolism of fructose in humans is similar to that in rats. Current evidence indicates that rats and humans are similar in this respect $[12,13]$. In the rat, the rate of fructose absorption is only $40 \%$ as fast as for glucose. This slow absorption of fructose ensures that fructose reaching the liver can be rapidly removed and metabolized without producing toxic effects in the liver $[14,15]$. The greater rise in insulin concentration relative to the rise in glucose concentration noted in the present study should facilitate a rapid removal of glucose by muscle and its storage as glycogen [16].

The glucose area determined after ingestion of an equimolar mixture of glucose and fructose was $54 \%$ of the area resulting from ingestion of the same total amount of hexose given as glucose alone. These data agree with the data obtained with glucose and fructose independently. Sucrose, consisting of equimolar fructose and glucose as the disaccharide, and orange juice, which contains approximately equal amounts of fructose, glucose and sucrose [8], produced glucose areas similar to that of the glucose and fructose mixture. These results could be anticipated from the composition of the sugars present. The rate of sucrose hydrolysis in the gut exceeds the rate of glucose and fructose absorption [17]. This observation helps explain the similarity of the responses to sucrose and the glucose-fructose mixture.

The similarity of the peak glucose following sucrose ingestion to that found following glucose ingestion is consistent with previous data indicating that the duration of increased glucose concentration correlates better with the amount of glucose consumed rather than the maximal glucose rise $[18,19]$. The contrast between these similar peak results for glucose and sucrose compared to the different 5-hour glucose areas for the two sugars indicates the importance of examining areas for five hours. This may also explain why others have reported post-sucrose meal glucose areas which approach those of a glucose meal. In the latter studies, the glucose concentration was only determined for $2-3 \mathrm{~h}$ after the meal [20-23]. One would expect, that the shorter the 
time interval studied, the less difference between the two would be found (manuscript in preparation).

The carbohydrate in apple juice is a mixture of about two-thirds fructose and one-third glucose (fructose $65 \%$, glucose $35 \%$ ) [24]. Thus, the modestly smaller post-meal glucose area following the ingestion of apples and apple juice (38\% and $32 \%$ of the glucose area) (Fig. 7) compared to the areas after orange juice, sucrose or an equimolar mixture of fructose and glucose $(63 \%$, $45 \%$, and $54 \%$ of the glucose area respectively) (Fig. 3) also can be explained by the composition of the carbohydrate in these meals. It also is apparent that the fibre present in the whole apple did not significantly influence the plasma glucose response. This is compatible with other data which indicate that the fibre present in naturally occurring foods has little effect on the postmeal glucose response [25].

The rather modest glucose increase following the ingestion of lactose (Fig. 8) was somewhat surprising, and is not readily explained by the composition of lactose or by current knowledge regarding the metabolism of lactose. In Caucasians, who generally are not milk intolerant, the rate of lactose hydrolysis in the intestine apparently exceeds the rate at which the products, glucose and galactose, can be absorbed [26]. Both glucose and galactose are rapidly absorbed, and galactose can readily be converted to glucose in the liver [27]. However, the quantitative importance of galactose conversion into glucose versus the storage of both galactose and glucose as glycogen has not been studied. Our observation of a maximal rise in glucose concentration at $1 \mathrm{~h}$ and the return to the fasting concentration by $3 \mathrm{~h}$ suggest that neither a delayed hydrolysis of lactose nor a delayed absorption of glucose can explain the results.

In addition, skim milk ingestion resulted in a plasma glucose curve which was almost identical to that after lactose ingestion, even though the insulin increase was nearly four times greater. The observed insulin area was nearly five times greater than the insulin area predicted by the glucose response.

The larger glucose area resulting from ice cream ingestion can be explained by the presence of glucose and sucrose in addition to lactose in this food product. The fat present might be expected to reduce the glucose response. However, in normal subjects the presence of a high fat content in a meal did not significantly affect the post-meal glucose curve after a single meal. It did reduce the glucose response to a second and third meal given the same day [29].

Overall, the data we have obtained to date would indicate that the single meal plasma glucose response is characteristic for each type of mono- or disaccharide in a food, and is little influenced by other constituents present in these meals.

The serum insulin response to the various carbohydrate foods was of considerable interest. If the plasma glucose excursion is used as a predictor of the serum insulin excursion, large discrepancies are observed be- tween the predicted and observed insulin values. This must be due to additional insulin secretagogues which are released in response to the meal. The differences between predicted and observed insulin response were particularly striking for fructose (4-fold), and skim milk (5-fold).

Fructose has been reported to potentiate glucose stimulation of insulin release in an isolated rat islet preparation [31]. In addition, the effectiveness of nonglucose insulin secretogogues such as arginine and isoproterenol have been shown to potentiate insulin secretion in the presence of an elevated glucose concentration. Galactose apparently does not stimulate insulin secretion directly or potentiate the effects of glucose on insulin secretion [32]. However, as we have demonstrated previously, animal protein is a potent insulin secretogogue in untreated Type 2 diabetic patients [3]. Thus, the presence of protein in milk and ice cream could largely explain the greatly increased insulin areas observed.

As we have pointed out previously [3, 28, 29, 33], these large increases in insulin concentration may have only a modest effect on the first meal glucose area, but may considerably reduce the glucose area of subsequent meals of the same composition ingested later in the day.

The present data, as well as previous data, indicate the need to consider the circulating insulin response to foods as well as the glycaemic response in designing a diet for non-insulin-requiring diabetic patients.

Acknowledgments. Supported by a grant from the Veterans Administration and funds from the National Dairy Board, administered in cooperation with the National Dairy Council. The authors wish to express their appreciation to the patients for their participation, and to the staff of the Special Diagnostic and Treatment Unit for their assistance in these studies. Dr. Krezowski was a Fellow in Endocrinology when these studies were conducted.

\section{References}

1. Otto H, Bleyer G, Penhartz M, Sabin G, Schauberger G, Spaethe K (1973) Kohlenhydrataustausch nach biologischen Äquivalenten. In: Otto H, Spaeth R (Hrsg) Diätetik bei Diabetes Mellitus. Huber, Bern, S 41-51

2. Jenkins DJA, Wolever TMS, Taylor RH, Barker $H$, Fielden $H$, Baldwin JM, Bowling AC, Newman HC, Jenkins AL, Goff DV (1981) Glycemic index of foods: a physiological basis for carbohydrate exchange. Am J Clin Nutr 34: 362-366

3. Nuttall FQ, Mooradian AD, Gannon MC, Billington C, Krezowski PA (1984) Effect of protein ingestion on the glucose and insulin response to a standardized oral glucose load. Diabetes Care 7: $465-470$

4. Nuttall FQ, Mooradian AD, DeMarais R, Parker S (1983) The glycemic effect of different meals approximately isocaloric and similar in protein, carbohydrate, and fat content as calculated using the ADA exchange list. Diabetes Care 6: 432-435

5. National Diabetes Data Group (1979) Classification and diagnosis of diabetes mellitus and other categories of glucose intolerance. Diabetes 28: 1039-1057

6. Watt BK, Merrill AL (1963) Composition of foods, Agricultural 
Research Service, USDA, Agricultural Handbook No 8. Washington, $\mathrm{DC}$

7. Paul AA, Southgate DAT (1978) McCance and Widdowson's: The Composition of Foods. 4th and revised and extended of MRC Special Report No 197. Elsevier/North Holland Biomedical Press

8. Harkinge MG, Swarner JB, Crooks H (1965) Carbohydrates in Foods. J Am Diet Assoc 46: 197-204

9. MacLean H (1932) Glycosuria and Diabetes, 5th edn. Constable \& Co Ltd, London

10. Akgun S, Ertel NH (1980) A comparison of carbohydrate metabolism after sucrose, sorbitol, and fructose meals in normal and diabetic subjects. Diabetes Care 3: 583-585

11. Crapo PA, Kolterman OG, Olefsky JM (1980) Effects of oral fructose in normal, diabetic, and impaired glucose tolerance subjects. Diabetes Care 3: 575-582

12. Nilsson LH, Hultman E (1974) Liver and muscle glycogen in man after glucose and fructose infusion. Scand $\mathrm{J}$ Clin Lab Invest 33: $5-10$

13. Bode JC, Bode C, Rumpelt HJ, Zelder O (1973) Loss of hepatic adenosine phosphates and metabolic consequences following fructose or sorbitol administration in man and in the rat. In: Regulation of hepatic metabolism. Munksgaard, Copenhagen, pp 267-281

14. Niewoehner CB, Gilboe DP, Nuttall GA, Nuttall FQ (1984) Metabolic effect of oral fructose in the liver of fasted rats. Am J Physiol 247: E505-E512

15. Niewoehner CB, Nuttall FQ (1986) Metabolic effects of dietary vs parenteral fructose. J Am Coll Nutr 5: 443-450

16. Nuttall FQ (1972) Mechanism of insulin action on glycogen synthesis. In: Steiner D, Frienkel N (eds) Handbook of physiology, vol 1, Endocrinology. The American Physiological Society, pp 395-413

17. Gary GM, Ingelfinger FJ (1966) Intestinal absorption of sucrose in man: Interrelation of hydrolysis and monosaccharide product absorption. J Clin Invest 45: 388-398

18. Christiansen NJ, Orskov H, Hansen AP (1972) Significance of glucose load in oral glucose tolerance tests. Acta Med Scand 192: 337-342

19. MacDonald I, Keyser A, Pacy D (1978) Some effects, in man, of varying the load of glucose, sucrose, fructose, or sorbitol on various metabolites in blood. Am J Clin Nutr 31: 1305-1311

20. Li BW, Schuhmann PJ (1983) Sugar analysis of fruit juices: Content and method. J Food Sci 48: 633-635, 653

21. Crapo PA, Kolterman O, Waldeck N, Reaven GM, Olefsky JM (1980) Postprandial hormonal responses to different types of complex carbohydrate in individuals with impaired glucose tolerance. Am J Clin Nutr 33: 1723-1728

22. Coulston A, Greenfield MS, Kraemer FB, Tobey TA, Reaven GM
(1981) Effect of differences in source of dietary carbohydrate on plasma glucose and insulin responses to meals in patients with impaired carbohydrate tolerance. Am J Clin Nutr 34: 2716-2720

23. Jenkins DJA, Wolever TMS, Jenkins AL, Thorne MJ, Lee R, Kalmusky J, Reichert R, Wong GS (1983) The glycaemic index of foods tested in diabetic patients: A new basis for carbohydrate exchange favouring the use of legumes. Diabetologia 24: 257-264

24. Simpson RW, McDonald J, Wahlquist ML, Atley L, Outch K (1985) Food physical factors have different metabolic effects in nondiabetics and diabetics. Am J Clin Nutr 42: 462-469

25. Nuttall FQ (1985) Fibres vegetales et regime diabetique. Journees de Diabetologie Hotel-Dieu. Flammarion Medecine-Sciences, $\mathrm{Pa}$ ris, pp 269-276

26. Williams CA, Phillips T, MacDonald I (1983) The influence of glucose on serum galactose levels in man. Metabolism 32: $250-256$

27. Segal S, Blair A (1961) Some observations on the metabolism of D-galactose in normal man. J Clin Invest 40: 2016-2020

28. Krezowski PA, Nuttall FQ, Gannon MC, Billington CJ, Parker S (1987) The insulin and glucose responses to various starch containing foods in type II diabetic subjects. Diabetes Care 10 (in press)

29. Nuttall FQ, Gannon MC, Wald JL, Ahmed M (1985) Plasma glucose and insulin profiles in normal subjects ingesting diets of varying carbohydrate, fat, and protein content. J Am Coll Nutr 4: $437-450$

30. Curry DL, Curry KP, Gomez M (1972) Fructose potentiation of insulin secretion. Endocrinology 91: 1493-1498

31. Ward WK, Beard JC, Halter JB, Pfeifer MA, Porte D Jr (1984) Pathophysiology of insulin secretion in non-insulin-dependent diabetes mellitus. Diabetes Care 7: 491-502

32. Grodsky GM, Batts AA, Bennett LL, Vcella C, McWilliams NB, Smith DF (1963) Effects of carbohydrates on secretion of insulin from isolated rat pancreas. Am J Physiol 205: 638-644

33. Ahmed M, Gannon MC, Nuttall FQ (1976) Postprandial plasma glucose, insulin, glucagon and triglyceride responses to a standard diet in normal subjects. Diabetologia 12: 61-67

Received: 28 May 1986

and in revised form: 15 September 1986

\section{Dr. Mary C.Gannon}

Nutritional Biochemist

Metabolic-Endocrine Section $(111 \mathrm{G})$

Minneapolis VA Medical Center

Minneapolis, Minnesota 55417

USA 